hoppy, and asures wo be is progreceine feroumbly, and feals most comfortable; ho has no great appotite for eolids, but he takes his tea, milk, pudding, otc., thankfully, and with apparent relish: still, wo shall remart, ho is inclined to sloep, which we probably attribute to the exhaustion caused by the frightful collapse symptoms (cramps, retching, etc.); and now and then there is very slight hiccup. The latter symptom has most frequently awakened me to the true state of matters, and has enabled me somewhat confidently, and long before any danger could otherwise have been anticipated, to form my prognosis. Sooner or later, unmistakeable febrile or typhoid symptoms make their appearance: then we have the ordinary difficulties of diagnosis and prognosis in typhus to deal with. It is in the earlier periods that the prognosis is often exceedingly difficult. $A$ just recognition of the more insidious and apparently less dangerous modes in which this stage begins I believe to be of great importance to the practitioner, inasmuch as, by affecting his treatment, the ultimate result of the disease is to a great extent controlled. For instance, after a very mild attack of cholera, marked by considerable serous purging, but by very slight romiting, and by the absence of cramps, where the condition familiarly known as collapse could scarcely be said to have existed, and without any distinct reaction stage, the patient appears in all respects (with the exception, let us say, of drowsiness or of occasional hiccup) to be convalescing. It is judged quite unnecessary to administer remedies of any kind, and alcoholic stimulants in particular are contra-indicated by the ruddy face and full pulse. The typhoid condition soon shows itself in unmistakeable characters, and now stimulants are given with all speed and in large quantity; but it is too late: the vital powers are already too far exhausted, and the patient dies. I question how far the non-exhibition of stimulants during reaction and the earlier stages of the consecutive fever has contributed to the fatal issue in many cases of cholera during this and former epidemics.

$$
\text { [To be continucd.] }
$$

Crichton Royal Institution, Dumfries, August 1854.

\section{ON THE FUNCTIONAL DISORDER OF THE ALIMENTARY CANAL NOW PREVAILING.}

By B. G. BABINGTON, M.D.

I BEG to direct the attention of the profession to a functional disorder of the alimentary canal, which, if not new in its characters, at least occurs under new circumstances, and at the present moment affects so many of the inhabitants of this metropolis as to lay some claim to being considered epidemic. Within the last fortnigbt, I have seen numerous cases; and I have reason to believe, from inquiries among my medical friends, that hundreds are at this time the subjects of the complaint in question. I allude to pain of a peculiar character, referred to the stomach in particular, and thence passing through to the back; sometimes extending under the false ribs on both sides; sometimes to the loins, especially over the kidneys; and sometimes to the lower bowels. It is more or less acute, being by some described as pricking or stabbing, while by others it is represented as uneasiness and general distress, necessitating a frequent change of posture. It has not affected the pulse, nor exhibited any inflammatory ormptoms, in the cases which have come under my observation; but I have heard from other medical men that they have in several instances been obliged, in addition to other antiphlogistic means, to have recourse to topical bleeding by leeches. It is neither attended by vomiting and nausea, nor necessarily by relaxation of the bowels; but it seems in every instance to have been accompenied by, and perhaps in no inconsiderable degree to be dependent on, the generation of flatus. This is not constant, but in some cases occurs two or three hours after taking food; while in others it takes place only late in the evening, and during the night. The complaint in martwed by neabe dobility and bo preasion of spirits.

The cause of this very unusual doriation from bralth, as existing with so much uniformity in such numerous ivstances, does not appear evident. At first I was disposed to attribute it to the unusual degree of ceution which the generality of persons have of late observed with respect to diet and beverage; many confining themselres up to the present time to bread and butter, fresh butcher's meat, and potatoes, as solid food; and to wine or brandy with water, as a beverage. It seemed not unlikely that the sudden discontinuance of fruits, raw or cooked, as well as of green vegetables and acids, might induce an alteration in the functions of the stomach and bowels-an approsech to the scorbutic diathesis favourable to the generation of flatus, and consequently to that state of distension of the stomach and bowels which I have described; but I have since found the complaint to exist in persons who have made no change whatever in their mode of living, and I am therefore constrained to acknowledge some other cause for its prevalence. Is it not possible that this may be found in some modification or dilution of that unknown something which, in certain predisposed persons, gives rise to cholera, and, in others, to what is called choleraic diarrhcea? I am prompted to ask this question from a consideration that there are other agents, poisonous or medicinal, which produce effects somewhat analogous to the ignotum quid, which causes cholera, according to the quantity administered. When, for example, but a small dose of calomel is taken, it will cause only nausea, flatulence, and tormina of the bowels; a larger dose will induce purging, and perhaps vomiting; while one still larger acts as a sedative, and might, if enormous, cause even fatal collapse. The same proportionate effects have beon frequently observed with other purgatives, as well as with the irritant poisons.

With respect to the treatment of this epidemic, although I have hardly as yet gained sufficient experience to speak with full confidence, yet I believe the following mode will generally be found adequate to effect its cure. If the bowels have been costive, I prescribe some such warm aperient as the following:-

B. Tincturæ rhei comp. $\zeta$ ss.

Tincturæ carlamomi comp. $3 \mathrm{j}$.

Infusi sennæ comp. 3 vij. ii.

Fiat haustus primo mane sumendus.

But whether this be noeded or not, I have known much benefit derived from the following carminative mixture:-

B Spiritus ammoriæe aromatici $j$ iij.

Tincturæ lavandulæ comp. $3^{\mathrm{iij}}$.

Tincturæ hyoscyami $3 \mathrm{jj}$.

Confectionis aromatic $3 \mathrm{ij}$.

Aqua cinnamomi ad $\zeta \mathrm{vj}$. $\mathrm{M}$.

Sumat cochl. ij ampla ter in die stomacho jejuno.

In addition to these means, I have only found it necessary to recommend a light nutritious diet, with a due admixture of well-boiled vegetables and cooked fruits; sherry and water, or brandy and water, being used as a beverage, in preference to malt liquor.

It will afford me much satisfaction if these imperfect remarks on this very prevalent, and, under the circumstances, novel form of indisposition, should attract the attention of my medical brethren, and lead to a more elaborate investigation of its nature and cause.

George Street, Hanover Square, Sept. 29th, 1854.

$$
\longrightarrow
$$

\section{IMPURE WATER AS A CAUSE OF DISEASE.}

$$
\text { By ALFRED CARPENTER, Esq., }
$$

Some observations made by Dr. Snow, upon the influence of water in the production of disense, bring to recollection facts observed by myself, and bear out what I have for como time maintained, that water in most frequently the vehicle by which the poison of continued forer and cholece 